\title{
Rethinking Public Value through the Lens of Sustainability
}

Amhøj, Christa Breum; Diamond, John; Olsen, Flemming

Document Version

Accepted author manuscript

Published in:

Local Economy

DOI:

$10.1177 / 0269094219886483$

Publication date:

2019

License

Unspecified

Citation for published version (APA):

Amhøj, C. B., Diamond, J., \& Olsen, F. (2019). Rethinking Public Value through the Lens of Sustainability. Local Economy, 34(6), 618-624. https://doi.org/10.1177/0269094219886483

Link to publication in CBS Research Portal

\section{General rights}

Copyright and moral rights for the publications made accessible in the public portal are retained by the authors and/or other copyright owners and it is a condition of accessing publications that users recognise and abide by the legal requirements associated with these rights.

Take down policy

If you believe that this document breaches copyright please contact us (research.lib@cbs.dk) providing details, and we will remove access to the work immediately and investigate your claim. 


\section{Rethinking Public Value through the Lens of Sustainability} Christa Breum Amhoj, John Diamond, and Flemming Olsen

Journal article (Accepted manuscript*)

\section{Please cite this article as:}

Amhøj, C. B., Diamond, J., \& Olsen, F. (2019). Rethinking Public Value through the Lens of Sustainability. Local Economy, 34(6), 618-624. https://doi.org/10.1177/0269094219886483

\section{DOl: https://doi.org/10.1177/0269094219886483}

Copyright (C) The Author(s) 2019. Reprinted by permission of SAGE Publications.

* This version of the article has been accepted for publication and undergone full peer review but has not been through the copyediting, typesetting, pagination and proofreading process, which may lead to differences between this version and the publisher's final version AKA Version of Record.

Uploaded to CBS Research Portal: June २०२० 


\title{
Viewpoint: Rethinking Public Value through the Lens of Sustainability
}

Christa Breum Amhøj, John Diamond and Flemming Olsen

\begin{abstract}
This Viewpoint outlines the context within which papers published in this and recent issues of Local Economy were initially presented, developed and then submitted. We suggest in the commentary below that from the outset (at an initial workshop) we were seeking to model an iterative and collaborative process. The policy context is described in more detail but the impetus came from looking at ways in which a policy and practice alliance focussed on the UNSDG could be mobilised to promote original thinking in the way in which municipal authorities could work with and learn from NGOs in the development of an alternative approach to sustainable development from that which currently shaped local social and economic policy in Copenhagen. This Viewpoint provides a summary of the papers published in Local Economy over two issues. It concludes by proposing that the approach adopted is in line with current initiatives in the USA and the UK.
\end{abstract}

Key words : sustainability ; collaboration ; innovation ; environmental risks ; participation ; alternative economic policy ; sustainable learning ; public value

\section{Introduction}

This Viewpoint comments on a collection of papers published in this and recent issues of Local Economy. It also provides an opportunity to reflect on and to examine the relationship between sustainability as a policy imperative as defined by international agencies and the actions and /or scope for innovation by practitioners and researchers working in and around the area of Copenhagen. The papers and think pieces referred to here are timely for a number of reasons. They reflect a growing sense of urgency that sustainability is not being taken seriously enough by many industrial nations and global leaders. They are a response (in part) to the widespread sense that whilst the language of reporting climate change may be changing the imperative to act differently has still not been taken up. They provide examples of how in one city policy and political decision making can be aligned to address particular questions and of original thinking about profound questions or assumptions that underpin industrial and advanced capitalist economies. Finally, they offer different ways of thinking about how policy makers as well as practitioners can be challenged and supported as they examine their room for change.

At the core of any contemporary discussion on sustainability are two questions. What part does economic growth, however defined, have to play? And what are the actions that need to be taken at an individual, neighbourhood or municipal level that will directly focus on the sustainability challenge? The papers are in different ways exploring how the understanding of growth is changing from its being a representation of values (e.g. in performance management systems) to something that we are doing together and something we need to do across formal roles, silos and organisational borders to catalyze and to provoke new and qualitatively better actions. 'Public Value' is not only an issue for public organizations, but about partnerships in the broad sense - 
connecting and creating new forms of on-going, self-generative and form-shifting hybrid networks. This is raising new kinds of questions about how to 'manage' - or rather about how to co-create and to become a part of - these sensitive and vibrant networks of Life.

\section{Context to the Workshop: In the City of Copenhagen}

The papers published by Local Economy are the result of an invitation by one of the authors of this Viewpoint to practitioners, researchers and professionals working in local government to participate in a workshop hosted by the Copenhagen Business School. The focus of the workshop was to explore the potential of bringing together different public policy processes with different ways of thinking spatially about the city and its environment (from neighbourhood to city region) alongside those who thought less in terms of public policy processes and structures but in a more organic and collaborative way of thinking and doing. There was a particular focus on working across conventional boundaries and systems with those who thought about how existing structures and processes including political decision making could be opened up - where the new space created supports creative and emergent process. In that sense we wanted to create a workshop in which its participants are taking their own medicine.

\section{Context of the Workshop: Beyond Copenhagen}

The workshop which brought those contributing to this issue together was deliberately intended to invite participants to think creatively about how the space or opportunity for open dialogue could be created. The discussions which followed at the initial workshop and then at two further sessions were dedicated to preparing the papers published in this journal and were successful in terms of the process of bringing together individuals from different experiences and backgrounds to listen, speak, engage and reflect on the challenges of policy formulation, adoption, and implementation.

The process of bringing together individuals with different assumptions, values and experiences in order to explore whether it is possible to arrive at mutually beneficial outcomes is not especially innovative or new. Indeed, all of the participants had experience of working in this way - there was a high value attached by all of them to collaboration and conscious and shared learning through critical self-reflection. For some of the group there was a positive shared history of joint working through research projects and initiatives across Copenhagen and the city region. From these experiences it became possible to encourage a more speculative and imaginative response to the invitation from the workshop organisers who have co-edited the papers published in Local Economy.

Through different experimental methods we wanted to catalyze and provoke new thoughts and experiences about sustainability. The intention of seeking to open up the conversation and the assessment of how sustainability (as defined through the adoption of the UN's Sustainable Development Goals (SDG) agenda) might be interpreted at the local (street) level as well as the city or regional level was not to create consensus. Rather, we wanted to critique in order to create, catalyze and provoke new actions. Some of these different kinds of actions, and of thinking, learning and organising, is to some extent reflected in the papers published across two issues of Local Economy. 
We did not only want to apply concepts in ways that identify and find 'problems'. We also wanted to use concepts to catalyze and to provoke new thoughts aimed at generating even more 'flat' and horizontal processes of organizing learning, knowledge and value with multiple bottom lines. We wanted theoretical concepts to be part of a process of creation. Sometimes in our discussions we named this idea about catalyzing thoughts in action as the action university (this idea is taken further by Christa and Flemming). This is a creative thinking-space where we are not only speaking about sustainable value creation, we are also trying to use performative methods to intensify the mere feeling of ideas, theoretical concepts and tensions. Intensifying vague and not yet articulated thoughts has a potential to create radical new knowledge. Thereby critique becomes affirmative; it becomes a matter of creating new thoughts. Because if something is radically new it has not yet been articulated through language.

\section{The Process We Chose: Catalyzing new thoughts in action}

From the initial workshop the authors worked their thoughts and ideas into papers which were then discussed at two more collaborative workshops. The published papers reflect this process. Taken together, the papers outline different ways of engaging with and thinking through the challenge for civic institutions, leaders and civil society of meeting the SDGs (working with civic institutions and NGOs is on-going and lead by Christa and Flemming). The papers draw on an eclectic mix of disciplines and theoretical frameworks. On one level we can see the process of bringing the authors and the papers together as iterative and 'messy'. It is iterative because with each reading or discussion ideas were being challenged and assumptions questioned. It was messy because with any inter-disciplinary process there is no linear pathway through different ways of thinking despite a deliberate focus on how an inter- disciplinary approach was understood and shared within the group.

The papers reflect their authors' different disciplinary and theoretical homes. We have all been encouraged to think creatively and to imagine different ways of responding to or framing the challenges posed by sustainability. Those that wanted to submit papers rewrote them or wrote a more detailed version of their presentation and met again to discuss the contributions and different ways of conceptualising sustainability within the specific spatial confines of Copenhagen but also as a policy framework to promote specific initiatives. The final session of the group included more detailed updating of the papers and extensive discussions on the different frameworks and ways of approaching the question of sustainability.

The final iterations of the papers are presented over two issues of Local Economy. Central to an appreciation of these papers is an understanding of the different disciplinary backgrounds of the contributors, their organisational affiliations and that they cut across different boundaries of academic researchers or practitioners working with NGOs on shared or related developments or policy makers with experience of working at a municipal level in city hall. This is why we have set out the iterative process.

The participants were encouraged to explore shared meanings and interpretations of 'sustainability' in the context of a city region thinking through the interplay between 'green growth' and local/ regional economic development. 
All in all the papers explore sustainability as a critique able to create, catalyze and to provoke new actions as on-going form-shifting and self-generative processes aiming at intensifying a qualitatively better Life. Some of these different kinds of actions are challenging our understanding of key social processes, implementation, strategy, value, learning, leadership and growth.

They are trying to rethink exiting theoretical concepts and ideas. They rethink and move our thoughts:

- From implementing sustainable goals to sustainability as on-going processes: the 'tactical level' becomes the strategic level - organizations need to be able to manage 'social movements';

- From process as 'discourses/language' to processes as hybrid networks of human and not human components;

- From plan and disruptions of the plan to unexpected processes as a potential resource;

- From geographical places to real felt and collective spaces;

- From formal Leadership to a collective and shared leadership;

- From instrumental knowledge to 'loose' knowledge as a resource.

\section{About the papers:}

In the paper: "Interpreting 'the social': exploring processes of social sustainability in Danish nonprofit housing" (Local Economy Volume 34, edition 5) Luise Li Langergaard demonstrates that working with social sustainability and the aims and ideals associated with it is not straightforward, since 'social sustainability' is not a tangible target, but rather something which is reinterpreted and subject to changing perceptions along with the process (Langergaard, L., 2019). The dynamic and changing character of 'sociality' suggests that social sustainability requires a focus on the conditions and on-going processes and interactions, which continuously constitute the social life and relations between residents in a neighborhood.

In Christa Amhøj's paper: "Sustainability as an ecology of learning, thinking and acting, Using the World Health Organization's six P's as an action-research intervention to create public value with multiple bottom lines" (Local Economy Volume 34, edition 5) it is argued that sustainability needs to become a verb - something we do (Amhøj, C., 2019). . The paper explores how to rethink theoretical concepts such as leadership, organizations, value and participation from a more sensitive, affective and aesthetic approach. Amhøj elaborates on how to turn these concepts into an action research process informed by World Health Organisation's Healthy Cities six P's (People, Participation, Place, Peace, Prosperity and Planet). The paper shows how the action research process create an "environ-mentality" where we move from the social production of individualised mentalities, controlling and disciplining our "selves" in relation to the expected norms. Instead the environ-mentalities informed to intensify and multiply intra-actions between human and nonhuman, animate or inanimate, virtual and actual, including bodies of knowledge-in or as a generative ecology of practices. The environ-mentality informs subjects to belong to and co-exist with a 'space' that is more than just a geographical place and to share, care, and take responsibility for how to develop an emerging ecology of a qualitatively better practice together. In other words, Amh $\varnothing \mathrm{j}$ is arguing that an ecology can be understood as a social technology, assuming collective care, belonging, co-existence and co-becoming, but without knowing what the practices are turning into. 
In the paper: "The gift economy and the development of sustainability", (this edition) Niels Thyge Thygesen shows how a new economic perspective - a gift economy - would be beneficial to the development of sustainability. The principles and practices of the gift economy (giving, receiving and reciprocating) are exemplified by a case study in the Danish island of Sams $\varnothing$, which has used it to achieve environmental sustainability, improve its economic situation and generate social value. In order to illustrate the values and principles that underpin the gift economy, the article shows the underlying exchange mechanisms used in this modern version of 'gift-giving' and contrasts them to using money as the medium of exchange.

In the paper "Urban nature as transformed practice", by Oleg Kofoed (this edition) it is argued that dramatic changes call for rethinking theory, practice, research, and engagement. The paper discusses all of those perspectives through the project NaTur i Byen (Nature in the City), which seeks to rework relations between sustainability, urban nature, eocologies, and economies. The discussion attempts to contribute to the understanding of how public value can be conceived in this complex, entangled field. The paper reveals an aspect of the theoretical and philosophical depth of this challenge and asks: what would it take to make change possible, without falling into the traps of (new) public management, commercial competition, defensive oppositional politics, or inefficiency of networks and communities? These questions lead us from theory into how to connect the question of transformed practice with the field of urban nature.

In the In Perspective paper "Collective movement or dead end stagnancy", Poula Helths (this edition) is showing that sustainability is a matter of transgressing instrumental rationality through aesthetic performance. Today's organisations are facing wicked problems which cannot be solved only with an instrumental rationality. Poula argues that catalyzing thoughts-in-the-act through creative and speculative methods can enable radical new approaches to managerial problems and challenges. All -in -all Poula shows that to examining and developing aesthetic performance as a basis for understanding of aesthetic rationality can create behavioural changes in the organisation.

In the paper "Sustainable Development Goals (SDGs) and Progressive Business Models for a 21st Century Local Economy" by Jacob Dahl Rendtorffs (this edition), it is argued, that a critical analysis of the possibilities of SDGs should support them to function as a vision and strategic tool for interdisciplinary economic development and for the management of business and public organizations and institutions for economic development and urban regeneration. The aim of the SDGs is to be an instrument for economic development and regeneration, which contribute to economic empowerment and social and political change. In this article, the goal is to investigate these possibilities of the SDGs to contribute to social innovation of the economy with the mobilization of business, public institutions and organizations, and NGOs. The paper also discuss some critical perspectives on: how the SDG compass that has been developed by the UN in order to encourage business organizations to follow and comply with the SDGs can be used locally. Here, we face the practical issues of orienting management in relation to the SDGs as the basis for developing local applications of the global SDGs.

\section{Conclusion}


We have set out the processes we and our co- authors engaged in because we think they were significant for three key reasons. Firstly, we wanted to create an environment in which ideas and ways of working could be explored in an open and participatory way. We recognised that in inviting the participants to the initial workshop we were quite consciously creating a multi- professional and multi- disciplinary group. This was important if the workshop was to stimulate different ways of thinking and planning. The core focus of the workshop was on how at a municipal level the UN goals for sustainable development could be enacted. Secondly, we recognise that the approach adopted in Copenhagen is not especially new or innovative. We see strong connections with the Green Deal initiative in the USA and a number of local economic policy developments in the UK centred around the work of the Centre for Local Economic Strategies (CLES) together with different but complementary initiatives based on promoting the idea of the co-operative council and the concept of drawing on the power and potential of key strategic institutions ( universities, public agencies ) in local areas to promote local economic development. Thirdly, we wanted to illustrate examples of different and thoughtful approaches to these complex and challenging questions - working across professional, disciplinary and organisational boundaries; framing the questions in terms of the potential to effect change; drawing on the shared ( not in any ownership sense ) assets which can be found in cities and neighbourhoods. We think this then leads to an analysis of how to create an alliance across different boundaries and ways of thinking in which the core question confronting us all is that of redressing the damage of climate change and offering an alternative social and economic model.

\section{References}

Amhøj, C. (2019) Sustainability as an ecology of learning, thinking and acting: Using the World Health Organization's six P's as an action-research intervention to create public value with multiple bottom lines. Local Economy 34 (5): 439-455

(Langergaards, L. (2019) Interpreting 'the social': Exploring processes of social sustainability in Danish nonprofit housing: Local Economy 34 (5): 456-470) 